\title{
Numerical Design and Frequency Response of all group-IV alloys based MQW Transistor Laser
}

Ravi Ranjan ( $\square$ ranjan275@gmail.com )

DCE: Darbhanga College of Engineering https://orcid.org/0000-0002-8153-392X

\section{Prakash Pareek}

Vishnu Institute of Technology

\section{Mukul Kumar Das}

Indian Institute of Technology (Indian School of Mines): Indian Institute of Technology

\section{Saurabh Kumar Pandey}

Indian Institute of Technology Patna

\section{Research Article}

Keywords: Transistor Laser, GeSn alloy, modulation bandwidth, multiple QW

Posted Date: February 19th, 2021

DOl: https://doi.org/10.21203/rs.3.rs-164636/v1

License: (c) (i) This work is licensed under a Creative Commons Attribution 4.0 International License. Read Full License

Version of Record: A version of this preprint was published at Journal of Computational Electronics on July 13th, 2021. See the published version at https://doi.org/10.1007/s10825-021-01732-5. 


\title{
Numerical Design and Frequency Response of all group-IV alloys based MQW Transistor Laser
}

\author{
${ }^{1}$ Ravi Ranjan ${ }^{*}$,Prakash Pareek, ${ }^{3}$ Mukul Kumar Das, and ${ }^{4}$ Saurabh Kumar Pandey \\ ${ }^{1}$ Departmet of EEE, Darbhanga College of Engineering Darbhanga, India, ${ }^{2}$ Department of ECE, Vishnu Institute \\ of Technology, Bhimavaram-534202, A.P., India, ${ }^{3}$ Department of Electronics Engineering, Indian Institute of \\ Technology (ISM), Dhanbad, India, ${ }^{4}$ Department of Electrical Engineering, India Institute of Technology Patna, \\ India \\ ("author for correspondence: email: ranjan275@gmail.com)
}

\begin{abstract}
In this work, a theoretical model is developed for n-p-n mid-infrared transistor laser (TL) with strain-balanced $\mathrm{Ge}_{0.85} \mathrm{Sn}_{0.15}$ multiple quantum well (MQW) structure in the base. Variation of optical confinement factor, modal gain and threshold current density have been rigorously investigated for different number of QWs (N) in MQW structure. The result shows that overall optical confinement factor and modal gain increase with $\mathrm{N}$. The frequency response of MQWTL for common base (CB) configuration is estimated from small signal relationship between the photon density and emitter current density by solving laser rate equation and continuity equation considering the virtual states as a conversion mechanism. Increment of $\mathrm{N}$ causes modulation bandwidth to initially increase and then decreases with $\mathrm{N}$, which reveals a shifting of device nature for higher values of $\mathrm{N}$. The results also suggest that on judicious selection of $\mathrm{N}$, the proposed device can become a viable monolithic light source.
\end{abstract}

Keywords : Transistor Laser, GeSn alloy, modulation bandwidth, multiple QW

\section{Introduction}

During the past few years, research on electronic photonic integrated circuit (EPIC) increased tremendously due to its potential features like low cost, high speed data processing etc [1,2]. In this regard many works have been reported which endeavour and implemented major parts of EPIC like detector, interconnects [3-5]. However, the quest of all group-IV optical sources is still not fulfilled which actually make the backbone of EPIC. It rightly said to be the ultimate milestone in the path to achieve the ultimate goal of monolithic integration with the current silicon platform [2].

This issue is addressed through development of light sources based on silicon photonics by different researchers lately. Some of the notable attempts in this context are silicon Raman lasers and Ge lasers [6-8]. However, they never become very popular as a proficient alternative of III-V material based light source. Fortunately, the surfacing of Group IV Photonics (GFP) as a viable platform for EPIC opens the door for realization of integrated light source [9].

Group IV alloys like SiGeSn and GeSn are emerging as major players in GFP [10]. The most significant property of theses alloys which divert the attention of researchers is the introduction of direct bandgap nature in GeSn, SiGeSn at an appropriate Sn content [11]. Moreover, the spectral response of these alloys span near and mid-IR region which ultimately make them a potential candidate to be used as active materials in midinfrared photonics device especially monolithic light source. In this context, authors had already proposed a theoretical model of such alloy based single QW transistor Laser (SQWTL) for the mid-infrared region [12]. The calculation of material gain and other performance parameters like modal gain, optical confinement factor, photon density, current gain etc. for SQWTL were also reported [12,13].

Unfortunately, the low value of optical confinement factor hampered the performance of single quantum well transistor laser (SQWTL) [13]. In order to circumvent this issue, concerned researchers introduced multiple quantum well (MQW) structure and performance parameters like threshold current density, current gain and output photon density were evaluated for $\mathrm{SiGeSn/GeSn} \mathrm{MQW} \mathrm{transistor} \mathrm{laser} \mathrm{[14-17].} \mathrm{The} \mathrm{frequency} \mathrm{response}$ prediction of MQWTL is very crucial in order to gauge its modulation bandwidth. Frequency domain analysis is 
already reported for III-V based MQWTL and SQWTL [18]. However, to the best of author's knowledge, a detailed transient analysis for group IV alloy based MQWTL which can forecast optimization for number of quantum well to obtain a suitable modulation bandwidth has not pursued yet in the literature.

Therefore, in this paper, authors proposed $\mathrm{GeSn} / \mathrm{SiGeSn}$ based MQW TL with proper design consideration followed by its small signal analysis. It is done by solving the laser rate equation and continuity equation simultaneously which includes the virtual states as a conversion mechanism [19]. The paper organized as follows. Section 2 describe the proposed model of group IV based MQW TL along with appropriate justifications. This section also provides brief summary of some preliminary study of MQW TL and corresponding results which serve as a preface for next section. Section 3 focuses on a detailed small signal analysis of $\mathrm{SiGeSn} / \mathrm{GeSn} \mathrm{MQW}$ TL supported by mathematical modeling. Results as obtained by methodology mentioned in section 3 are depicted and discussed thoroughly in section 4. Finally, some salient conclusions of present work are provided in section 5.

\section{Model Description and its preliminary study}

The schematic structure of proposed group IV based MQWTL is shown in Fig.1. The n-type Ge, p-type $\mathrm{Si}_{0.12} \mathrm{Ge}_{0.73} \mathrm{Sn}_{0.15}$ and n-type $\mathrm{Si}_{0.11} \mathrm{Ge}_{0.73} \mathrm{Sn}_{.16}$ respectively serve as emitter, base and collector of the device. It may be relevant to mention here that the aforementioned constituents of $\mathrm{Si}$, Ge and $\mathrm{Sn}$ in base and collector are chosen to achieve desirable optical confinement [12]. Multiple (N) numbers of intrinsic active $\mathrm{Ge}_{0.85} \mathrm{Sn}_{0.15}$ quantum well layers are inserted in the base at a regular spacing to form the quantum well structure with alternate barrier and well region.

In order to minimize the strain, this quantum well structure is engineered in the following manner to form a strain balanced structure. Compressive strain of each GeSn well is counter balanced by the same amount of tensile strain in each SiGeSn barrier. As a result, the overall multiple quantum well structure is strain balanced with respect to the relaxed GeSn buffer layer. The quantum well region with constituent $\mathrm{Ge}_{0.85} \mathrm{Sn}_{0.15}$ is considered to achieve direct band gap material. Significant carrier and optical confinement are obtained and lasing action occurs in this region. The collector layer is lattice matched with buffer layer and placed in between the base and the buffer layer. The growth axis is assumed to be along the z-direction. The widths of the barrier and the well are selected as $10 \mathrm{~nm}$ to ensure single bound state in each quantum well and also to facilitate the

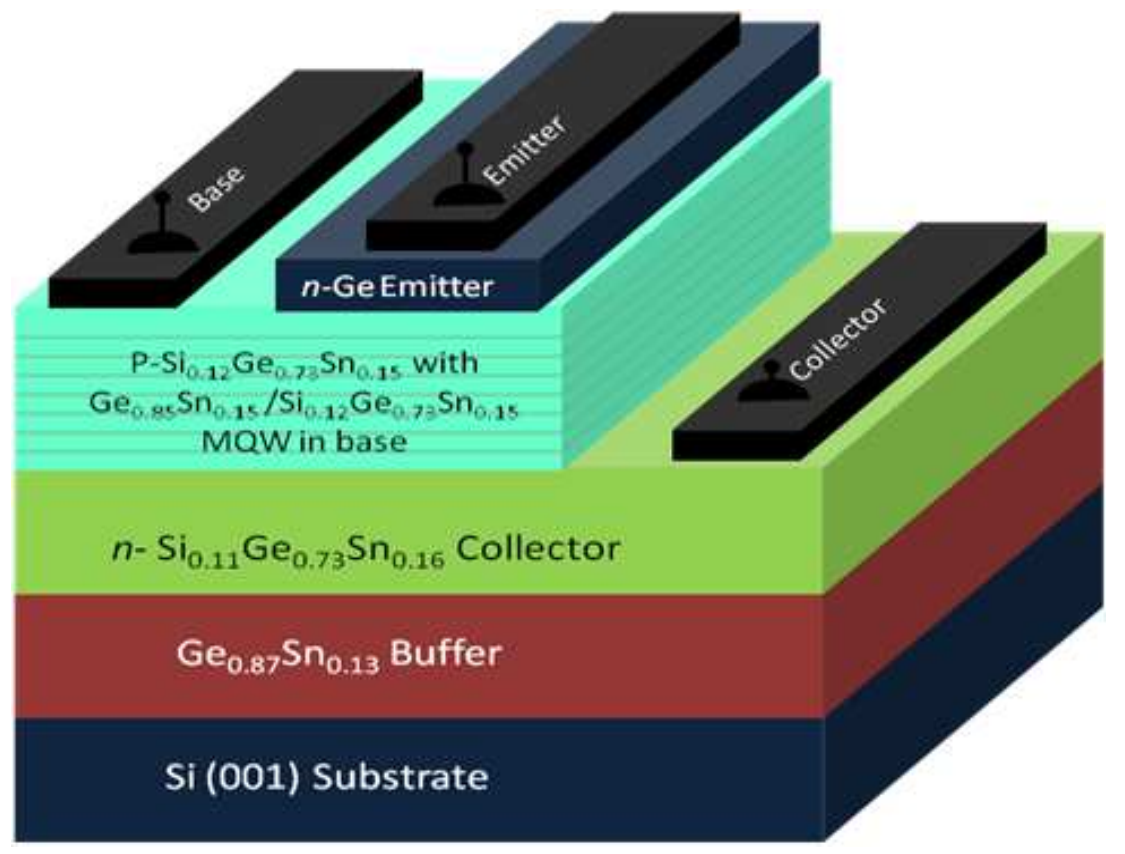

Fig.1. Schematic structure of $n p n \mathrm{Ge}_{-} \mathrm{Si}_{0.12} \mathrm{Ge}_{0.73} \mathrm{Sn}_{0.15^{-}} \mathrm{Si}_{0.11} \mathrm{Ge}_{0.73} \mathrm{Sn}_{0.16}$ based transistor laser (TL) with strain-balanced $i-\mathrm{Ge}_{0,85} \mathrm{Sn}_{0.15}$ multiple quantum wells (MQW) in the base. 
strain balanced condition of the whole structure.

The model solid theory is used to calculate the band structure of $\Gamma$ and $\mathrm{L}$ valley of conduction band, heavy hole valence band $(\mathrm{HH})$ and light hole valence band $(\mathrm{LH})$ in well and barrier [12,20]. The calculated band structure is used to find the quantized energy and corresponding wave function in $\Gamma$ conduction band and $\mathrm{HH}$ valence band. The TE polarized material gain is also estimated at the band edges in the QW with the help of Fermi golden rule [12]. The modal gain which depends on the optical confinement factor of the active layer is calculated using finite element method (FEM) based simulation of the structure, as reported elsewhere [13]. The threshold modal gain for the single QW structure is calculated using the free carrier absorption loss. The main limitation with the single QW structure is its very less optical confinement factor which is in the tune of $2.5 \%$ as reported earlier [13].

Therefore, in order to tackle this issue, MQW structure is introduced in the base of TL. In MQWTL structure, the overall optical confinement factor $\left(\Gamma_{\mathrm{w}}\right)$ in the active region is increased. Increment in $\Gamma_{\mathrm{w}}$ is due to increase in effective area of active region due to introduction of a greater number of quantum wells. The optical confinement factor of the different layers is also altered due to the higher area acquired by QWs. As a result, the modal loss in MQW structure also varies as a function of number of wells in the base. Optical confinement

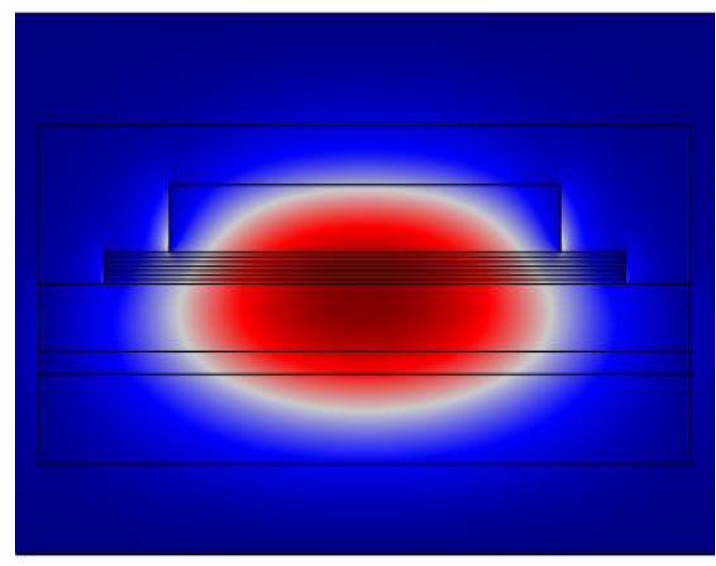

(a)

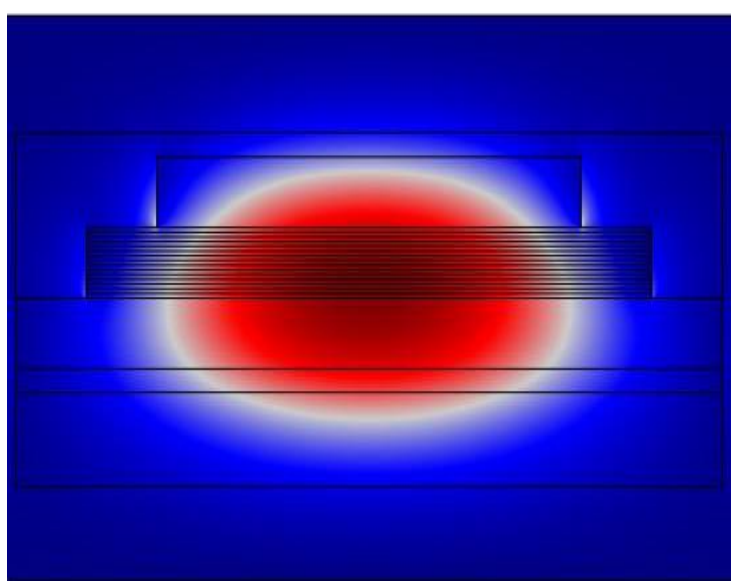

(c)

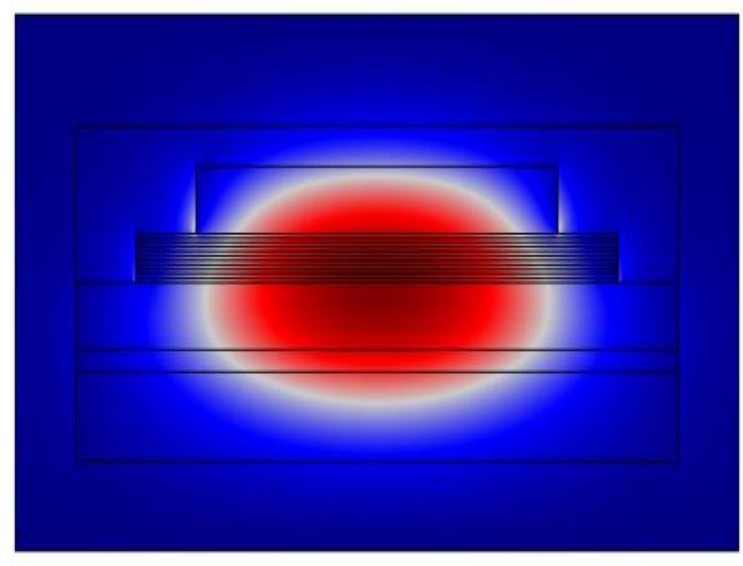

(b)

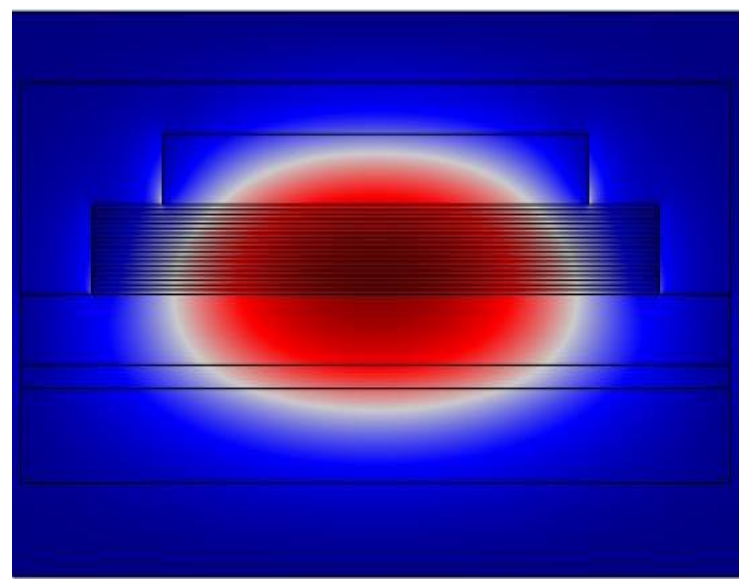

(d)

Fig.2. Field distribution of the TE field $E_{x}$ for the quasi-TE fundamental mode at $\lambda=2.68 \mu \mathrm{m}$. The peak transverse electrical field is located near the active region, providing a $\mathrm{QW}$ optical confinement factor of (a) $7.07 \%$ for $\mathrm{N}=3$ (b) $11.4 \%$ for $\mathrm{N}=3$ (c) $15.5 \%$ for $\mathrm{N}=3$ (d) $19.00 \%$ for $\mathrm{N}=3$ 
factor $\left(\Gamma_{\mathrm{w}}\right)$, in different layers, is determined by using FEM based simulation of the structure. Then the modal loss of different layers is calculated using $\Gamma_{\mathrm{w}}$ and free carrier absorption for different layers [13].

Since the $\Gamma_{\mathrm{w}}$ in different layers vary with the number of QWs $(\mathrm{N})$, the TL structure is simulated for a particular value of $\mathrm{N}$ (say N=3, 5, 7 and 9) and performance of MQWTL is analyzed. The Field distribution of the TE field $E_{x}$ for the quasi-TE fundamental mode at $\lambda=2.68 \mu \mathrm{m}$ in waveguide for MQWTL (N=3, 5, 7 and 9) is shown in Fig. 2 (a)-(d). The peak transverse electrical field is located near the active region and the field distribution clearly indicates an increment in optical confinement factor with the number of QW. Estimated values of optical confinement factor for different number of QWs are: (a) 7.07\% for $\mathrm{N}=3$ (b) $11.4 \%$ for $\mathrm{N}=5$ (c) $15.5 \%$ for $\mathrm{N}=7$ (d) $19.00 \%$ for $\mathrm{N}=9$. However, the effective optical confinement factor per well $(2.37 \%$ for $\mathrm{N}=3$, $2.29 \%$ for $\mathrm{N}=5,2.21 \%$ for $\mathrm{N}=7$ and $2.07 \%$ for $\mathrm{N}=9$ ) decreases with increasing $\mathrm{N}$. Therefore, in this work, maximum value of $\mathrm{N}$ is considered as 9 .

The optical confinement factor and free carrier absorption loss in the emitter, base, collector contact layer and well are evaluated and summarized in Table 1, for different $\mathrm{N}$. The mirror loss is calculated by considering the cavity length of the waveguide as $500 \mu \mathrm{m}$ and the reflectivities of both facets $\left(R_{1} \& R_{2}\right)$ as 1 and 0.7 respectively and it remain same regardless of $\mathrm{N}$. The total loss, including the mirror loss and free carrier absorption loss is obtained as $57.67 \mathrm{~cm}^{-1}, 51.94 \mathrm{~cm}^{-1}, 46.98 \mathrm{~cm}^{-1}$ and $42.10 \mathrm{~cm}^{-1}$ respectively for $\mathrm{N}=3,5,7$ and 9 [13].

Table 1: Calculated optical confinement factor and absorption loss in emitter, base, collector contact layers and well for different $\mathrm{N}$

\begin{tabular}{|c|c|c|c|c|}
\hline \multicolumn{5}{|c|}{$\mathbf{N}=3$} \\
\hline & $\begin{array}{l}\text { Base contact } \\
\text { layer }\end{array}$ & $\begin{array}{c}\text { Emitter Contact } \\
\text { Layer }\end{array}$ & $\begin{array}{l}\text { Collector } \\
\text { contact layer }\end{array}$ & Well \\
\hline $\begin{array}{l}\text { Free Carrier absorption } \\
\left(\mathrm{cm}^{-1}\right)\end{array}$ & 478.973 & 244.115 & 0.2308 & 14.569 \\
\hline $\begin{array}{l}\text { Optical Confinement } \\
\text { factor }\end{array}$ & 0.021 & 0.176 & 0.386 & 0.070 \\
\hline Absorption loss $\left(\mathrm{cm}^{-1}\right)$ & 9.996 & 42.988 & 0.089 & 1.031 \\
\hline \multicolumn{5}{|c|}{$\mathrm{N}=5$} \\
\hline $\begin{array}{l}\text { Optical Confinement } \\
\text { factor }\end{array}$ & 0.019 & 0.1543 & 0.362 & 0.115 \\
\hline Absorption loss $\left(\mathrm{cm}^{-1}\right)$ & 8.956 & 37.666 & 0.084 & 1.669 \\
\hline \multicolumn{5}{|c|}{$\mathrm{N}=7$} \\
\hline $\begin{array}{l}\text { Optical Confinement } \\
\text { factor }\end{array}$ & 0.017 & 0.135 & 0.337 & 0.155 \\
\hline Absorption loss $\left(\mathrm{cm}^{-1}\right)$ & 8.046 & 33.0287 & 0.0778 & 2.26 \\
\hline \multicolumn{5}{|c|}{$\mathrm{N}=9$} \\
\hline $\begin{array}{l}\text { Optical Confinement } \\
\text { factor }\end{array}$ & 0.015 & 0.117 & 0.308 & 0.19 \\
\hline Absorption loss $\left(\mathrm{cm}^{-1}\right)$ & 7.113 & 28.583 & 0.0712 & 2.769 \\
\hline
\end{tabular}

After calculation of optical confinement factor and modal loss, modal gain and the threshold modal gain are calculated to predict the threshold carrier density $\left(\mathrm{N}_{\text {th }}\right)$. The threshold modal gain is considered to be equal to the modal loss. The variation of modal gain as a function of total injected carrier density for different $\mathrm{N}$ is plotted and shown in Fig. 3. The modal gain increases with the number of QW, as the overall optical confinement factor increases. However, from the figure, it is also observed that the rate of increment of modal gain with $\mathrm{N}$ is decreasing because the effective optical confinement factor per well decreases with $\mathrm{N}$ as pointed out earlier. The effect of $\mathrm{N}$ on $\mathrm{N}_{\mathrm{th}}$ can be visualized in Fig.4 where the plot of threshold carrier density as a function of $\mathrm{N}$ is shown. This figure clearly depicts that initially for smaller values of $\mathrm{N}, \mathrm{N}_{\mathrm{th}}$ decreases very rapidly but after that, it almost saturates with increasing $\mathrm{N}$. 


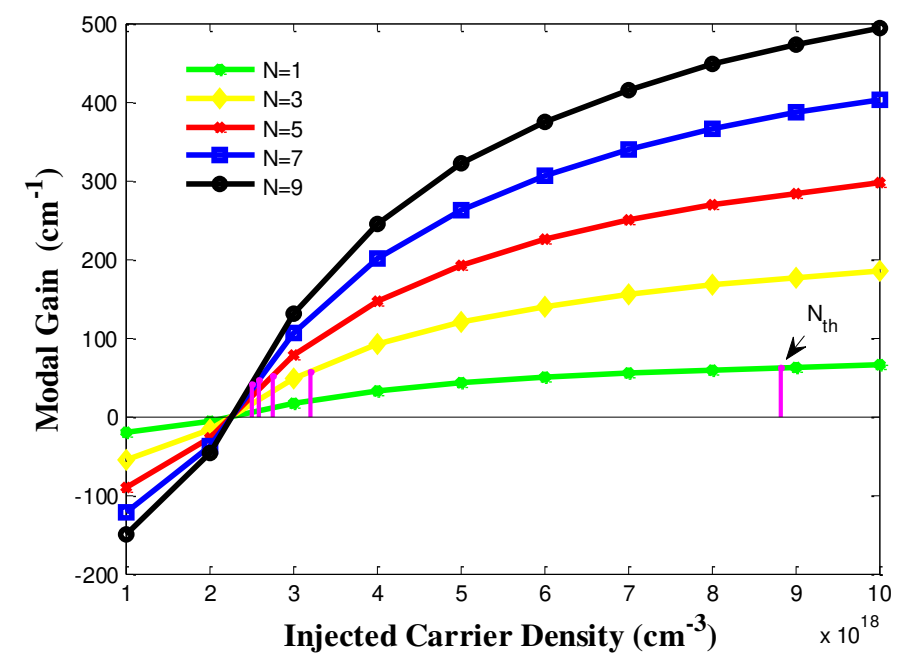

Fig.3. Plot of modal gain as a function of injected carrier density to obtained threshold carrier density

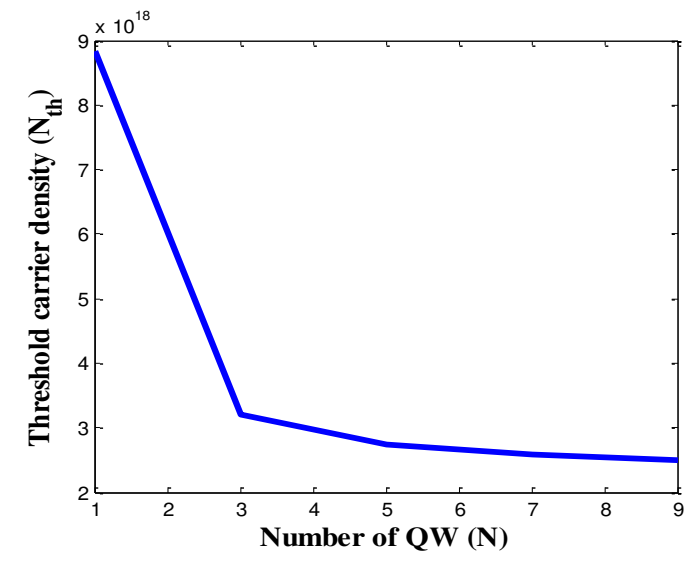

Fig 4. Threshold carrier density as a function of number of QW

\section{Small Signal Analysis}

In the present analysis, the transistor is assumed to be operated in normal active mode and diffusion is the dominant carrier transfer mechanism. The schematic of the carrier diffusion as well as energy band of $\Gamma$ conduction band and $\mathrm{HH}$-valence band under bias is shown in Fig. 5. In the figure, $\mathrm{W}_{\mathrm{B}}$ is the width of the base and $\mathrm{x}=-\mathrm{W}_{\mathrm{B}} / 2, \mathrm{x}=\mathrm{W}_{\mathrm{B}} / 2$ is the position of the emitter-base (EB) and the collector-base (CB) junction respectively. The widths of well and barrier are $\mathrm{d}$ and $\mathrm{W}_{\mathrm{b}}$ respectively. The position of an arbitrary $\mathrm{n}^{\text {th }}$ well can be expressed as:

$$
x_{n}=-\frac{W_{b}}{2}+n W_{b}+(n-1) d+\frac{d}{2}
$$

Due to the forward biased base-emitter junction, carriers (electrons) are injected from the emitter into the base (barrier). Some of the unbound injected minority carriers are quantum captured into the bound state at the first QW with a capture probability, $1 / \tau_{\text {cap }}$ and rest diffuse to the next QW. After several captures at different QWs, carriers reach the collector and they are swept out due to reverse biased base-collector junction. Some carriers may also escape from QW with a lifetime, $\tau_{\text {ese. }}$

During transport of carriers through wells and barriers, the inter-well coupling is not considered in this analysis and hence the effective inter-well transport time $\left(\tau_{c}\right)$ is ignored. The appropriate justification for this is as 
follows. The inter-well coupling effect on carrier transport depends on the energy height of the barrier and thickness of the well [21,22] and mathematically it is expressed by tunneling time $\left(\tau_{t}\right)$. In the proposed MQWTL, the energy height of the barrier is very low $(0.0712 \mathrm{eV})$. Therefore, the escape lifetime is dominant over tunneling time and hence $\tau_{\mathrm{c}}$ is not included in the calculation.

The small signal analysis is very crucial to attain frequency response and later the modulation bandwidth of the device. The excess minority carrier density in the base can be expressed as,

$$
\delta n=\delta N_{0}+\delta n e^{j \omega t}
$$

Where, $\delta \mathrm{N}_{0}$ is steady state-solution of the diffusion equation, $\delta \mathrm{n}$ is amplitude of small-signal component and $\omega$ is angular frequency. In the presence of small-signal sinusoidal modulation, the diffusion equation for the excess minority carriers in the base region can be written as,

$$
j \omega \delta n=D_{n} \frac{\partial^{2} \delta n}{\partial x^{2}}-\frac{\delta n}{\tau_{B}}
$$

where, $\mathrm{D}_{\mathrm{n}}$ is the diffusion constant coefficient of electrons in the base and $\tau_{B}$ is the carrier lifetime in the base region. Eqn. (3) is solved with the following boundary conditions.

$$
\begin{aligned}
& j_{e}=q D_{n} \frac{\partial \delta n}{\partial x}, \quad x=-\frac{W_{B}}{2} \\
& j_{c}=q D_{n} \frac{\partial \delta n}{\partial x}, \quad x=\frac{W_{B}}{2} \\
& \delta n\left(x_{n}^{-}\right)=\delta n\left(x_{n}^{+}\right)=n_{V \cdot S_{n}} \\
& j_{V \cdot S n}=q D_{n} \frac{\partial \delta\left(x_{n}^{-}\right)}{\partial x}-q D_{n} \frac{\partial \delta\left(x_{n}^{+}\right)}{\partial x} \\
& j_{e}=j_{c}+j_{b}
\end{aligned}
$$

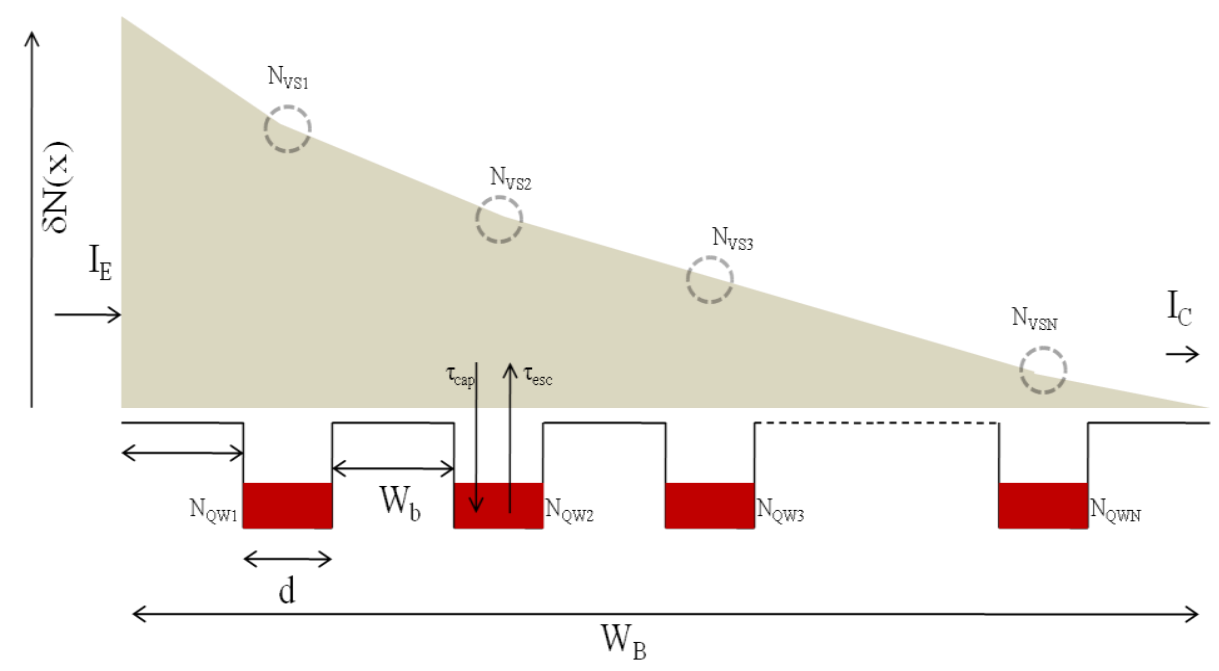

Fig.5: Schematic of carrier diffusion, quantum capture and escape in the MQW transistor laser 
where, $j_{e}$ and $j_{c}$ are the emitter and collector current densities at $x=-W_{B} / 2$ and $x=W_{B} / 2$ respectively, $W_{B}$ is the total base width, $n_{V . S n}$ is the virtual state carrier concentration at $x=x_{n}, j_{V . S n}$ is the virtual state current density at $x=x_{n}, J_{B}$ is the base current density. The conventional laser rate equations in the $\mathrm{n}^{\text {th }}$ active region can be written as,

$$
\begin{aligned}
& \frac{d s_{n}}{d t}=\left(\Gamma_{w} G_{0}\left(n_{q w n}-n_{t r n}\right)-\frac{1}{\tau_{p}}\right) s_{n}+\Gamma_{w} R_{s p} \\
& \frac{d n_{q w n}}{d t}=\frac{j_{q w n}}{q d}-\frac{n_{q w n}}{\tau_{s}}-G_{0}\left(n_{q w n}-n_{t r n}\right) s_{n}
\end{aligned}
$$

where, $s_{n}$ is the photon density, $n_{q w n}$ is the QW carrier density, $n_{t r n}$ is the transparency carrier density, $G_{0}$ is the differential optical gain, $R_{s p}$ is the spontaneous emission factor, $\Gamma_{w}$ is the optical confinement factor in well, $\tau_{p}$ is the photon lifetime, $\tau_{s}$ is the carrier recombination lifetime in $\mathrm{QW}$ and $j_{q w n}$ is the current density in QW energy state for $\mathrm{n}^{\text {th }}$ well. The rate equations which relates bulk minority carrier with 2D-QW carriers are:

$$
\begin{aligned}
& \frac{d n_{V . S_{-} n}}{d t}=\frac{j_{v . s_{-} n}}{q d}-\frac{j_{q w_{-} n}}{q d}-\frac{n_{V . S_{-} n}}{\tau_{S}} \\
& \frac{j_{q w_{-} n}}{q d}=\frac{n_{v_{. s_{-}} n}}{\tau_{\text {cap_n }}}-\frac{n_{q w_{-} n}}{\tau_{\text {esc }}}
\end{aligned}
$$

where, $\tau_{c a p}$ and $\tau_{e s c}$ are the capture and escape lifetime of the carriers from the virtual states to QW and viceversa respectively. The modulation bandwidth of MQW TL in the common base (CB) configuration is obtain by calculating the $\mathrm{CB}$ modulation transfer function $[\mathrm{s}(\mathrm{j} \omega) / \mathrm{je}(\mathrm{j} \omega)]$. After solving Eqn. 2 to 12 for small signal component (AC component) the relationship between photon density and emitter current in frequency domain is obtained. Based on this relationship, the transfer function can now be written as

$$
\begin{gathered}
H(j \omega)=\frac{\cosh \left(\frac{x_{1}+\frac{W_{B}}{2}}{L_{D}}\right)}{H_{2}(j \omega)}+\frac{\left(\frac{q D_{n}}{L_{D}}\right) \sinh \left(\frac{x_{1}+\frac{W_{B}}{2}}{L_{D}}\right)}{H_{3}(j \omega)}-\frac{\left(\frac{q D_{n}}{L_{D}}\right) \cosh \left(\frac{x_{1}+\frac{W_{B}}{2}}{L_{D}}\right) \operatorname{coth}\left(\frac{x_{1}-x_{2}}{L_{D}}\right)}{H_{3}(j \omega)} \\
+\frac{\left(\frac{q D_{n}}{L_{D}}\right)\left(\cosh \left(\frac{x_{1}+\frac{W_{B}}{2}}{L_{D}}\right) / \sinh \left(\frac{x_{1}-x_{2}}{L_{D}}\right)\right)}{H_{3}(j \omega)}
\end{gathered}
$$

where, $H_{1}(j \omega)=\frac{s}{j_{q w_{-} n}}=\frac{-\left(\Gamma_{w} G_{0} S_{0} / q d\right)}{\omega^{2}-j \omega\left(1 / \tau_{s}-G_{0} S_{0}\right)-\left(G_{0} S_{0} / \tau_{p}\right)}$

$$
\begin{array}{r}
H_{2}(j \omega)=\frac{s}{j_{v s_{-} n}}=\frac{1}{\left.\left.\llbracket 1+\left(\tau_{c a p_{-} n} / \tau_{s}\right)+j \tau_{c a p_{-} n} \omega\right] / H_{1}(j \omega)\right]+} \\
\left.\left.\llbracket q d\left(\tau_{c a p_{-} n} / \tau_{e s c}\right)\left(j \omega+\left(1 / \tau_{s}\right)\right)\right] /\left(\Gamma_{w} G_{0} S_{0} / j \omega\right)\right]
\end{array}
$$

$$
H_{3}(j \omega)=\frac{s}{n_{v s_{-} n}}=\frac{1}{\left(\tau_{c a p_{-}} / \tau_{e s c}\right)\left(1 /\left(\Gamma_{w} G_{0} S_{0} / j \omega\right)\right)+\left(\tau_{\text {esc }} / q d\right)\left(1 / H_{1}(j \omega)\right)}
$$


Here the transfer function $\mathrm{H}_{1}(\mathrm{j} \omega)$ is intrinsic response between photon and QW current density which does not include the carrier capture and escape process. $\mathrm{H}_{2}(\mathrm{j} \omega)$ and $\mathrm{H}_{3}(\mathrm{j} \omega)$ are the transfer functions relate the photon and virtual state current and carrier concentration density. Actually, these transfer functions include the effect of carrier capture and escape process from the QW to virtual state and vice versa.

\section{Results and discussion}

Calculation of relevant material and device parameters for MQWTL is very important before estimation of its modulation response. Some material and device parameter values are same for both single QW and multi QW configuration based TL. Therefore, in this work these values are considered same as that for single QWTL reported elsewhere [7]. However, there are also few relevant device parameters that vary with the number of QWs (N). These parameters are obtained for different $\mathrm{N}$ and are listed in Table 2.

Table 2:Values of some device parameters for different QWs (N)

\begin{tabular}{|l|l|l|l|l|l|}
\hline Parameter & $\mathbf{N}=\mathbf{1}$ & $\mathbf{N}=\mathbf{3}$ & $\mathbf{N}=\mathbf{5}$ & $\mathbf{N}=\mathbf{7}$ & $\mathbf{N}=9$ \\
\hline $\begin{array}{l}\text { Carrier Capture } \\
\text { lifetime }\left(\boldsymbol{\tau}_{\text {cap }} \text { in ps }\right)\end{array}$ & 0.50 & 1.17 & 1.83 & 2.50 & 3.17 \\
\hline $\begin{array}{l}\text { Differential Optical } \\
\text { Gain }\left(\mathbf{G}_{\mathbf{0}} \text { in cm } \mathrm{cm}^{-1}\right)\end{array}$ & $2.71 \times 10^{-6}$ & $5.94 \times 10^{-6}$ & $6.48 \times 10^{-6}$ & $6.50 \times 10^{-6}$ & $6.55 \times 10^{-6}$ \\
\hline $\begin{array}{l}\text { Threshold Carrier } \\
\text { Density }\left(\mathbf{N}_{\text {th }} \text { in } \mathrm{cm}^{-3}\right)\end{array}$ & $8.83 \times 10^{18}$ & $3.21 \times 10^{18}$ & $2.75 \times 10^{18}$ & $2.58 \times 10^{18}$ & $2.50 \times 10^{18}$ \\
\hline $\begin{array}{l}\text { Transparency carrier } \\
\text { density }\left(\mathbf{N}_{\text {tr }} \text { in } \mathrm{cm}^{-3}\right)\end{array}$ & $2.51 \times 10^{18}$ & $2.26 \times 10^{18}$ & $2.26 \times 10^{18}$ & $2.26 \times 10^{18}$ & $2.26 \times 10^{18}$ \\
\hline $\begin{array}{l}\text { Optical Confinement } \\
\text { Factor }(\boldsymbol{\Gamma})\end{array}$ & 0.0245 & 0.07077 & 0.11458 & 0.15513 & 0.1900 \\
\hline
\end{tabular}

After obtaining all the material and device parameters, modulation response at $J_{B}=4 \mathrm{kA} / \mathrm{cm}^{2}$ is evaluated with the help of Eq.13. The modulation response is plotted in terms of output photon density variation as a function of base current density for different $\mathrm{N}$ and is shown in Fig.6. The vertical line in the figure represents the values of output photon density at $\mathrm{J}_{\mathrm{B}}=4 \mathrm{kA} / \mathrm{cm}^{2}$ for different $\mathrm{N}$. It can be clearly observed from the figure that photon density increases with number of QW. The small-signal modulation response for the $\mathrm{CB}$ configuration is also shown in Fig. 7. It is depicted from the figure that with increasing number of well $(\mathrm{N})$, initially the modulation bandwidth increases with $\mathrm{N}$. Then after reaching its maximum, the modulation bandwidth starts to decreases. This trend can be justified as follows. Since the optical confinement factor increases with N, it causes the modal gain to surge too. Due to this enhancement of modal gain, threshold base current density $\left(\mathrm{J}_{\mathrm{Bth}}\right)$ decreases and

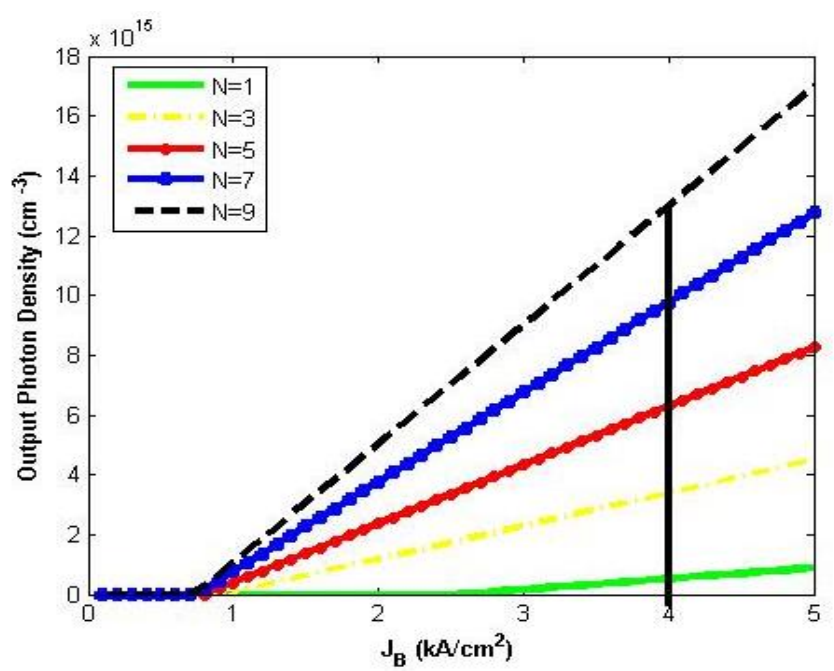

Fig.6.Plot of output photon density as a function of base current density for different $\mathrm{N}$ number of well 


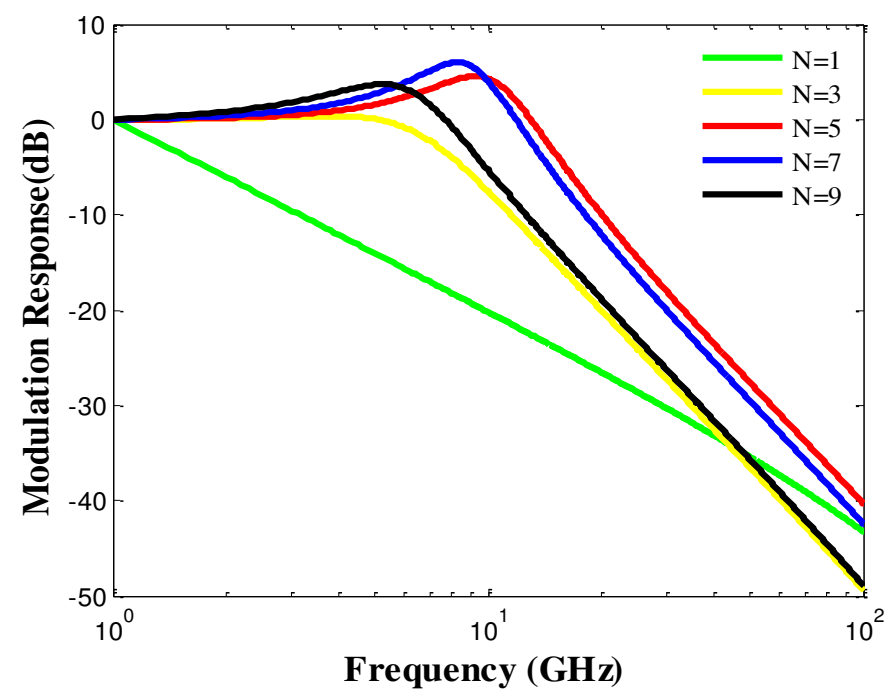

Fig.7. Modulation response with frequency for different number of QW

consequently, a higher modulation bandwidth is obtained. However, the higher values of $\mathrm{N}$ induce a shift in the

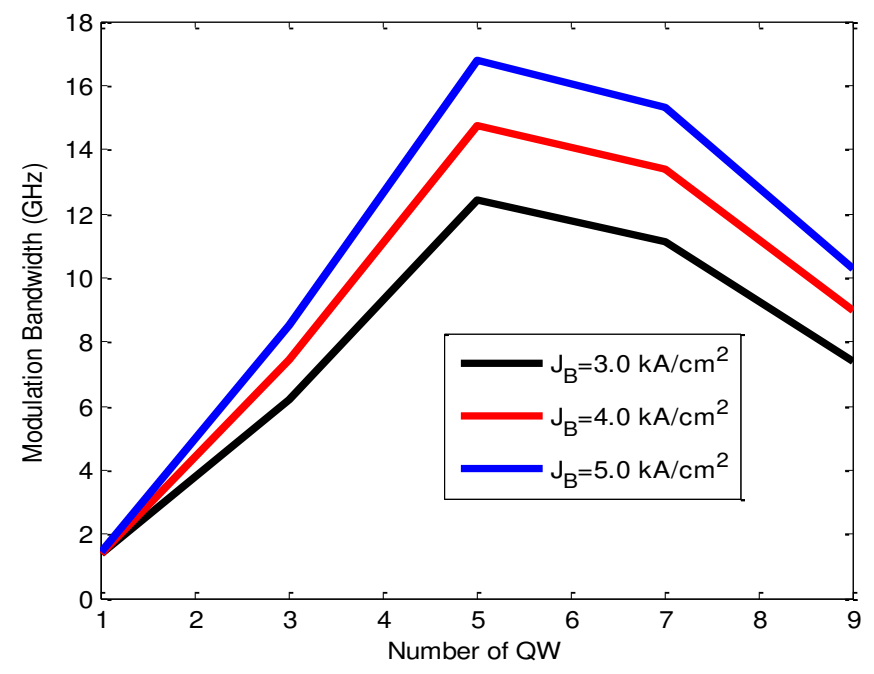

Fig.8. Modulation Bandwidth plotted as a function of number of well for different current density

nature of the device from transistor laser to diode laser (DL). Thus, after higher values of N, the modulation bandwidth as well as resonance frequency, starts decreasing. In order to have better understanding of this phenomenon, the 3-dB modulation bandwidth is plotted as a function of number of QWs $(N)$ for different $J_{B}$ and shown in Fig. 8. The figure portrays that maximum modulation bandwidth is obtained as $14.7 \mathrm{GHz}$ at $\mathrm{N}=5 \mathrm{for}$ $\mathrm{J}_{\mathrm{B}}=4 \mathrm{kA} / \mathrm{cm}^{2}$. Moreover, it can also be seen from the figure that the modulation bandwidth increases for higher current densities However the maximum modulation bandwidth is obtained at $\mathrm{N}=5$, and then it reduces further on increasing $\mathrm{N}$. Thus, the choice of $\mathrm{N}$ is very important to obtain enhanced performance of MQWTL.

\section{Conclusion}

This work attempts to investigate the frequency response for tin incorporated group-IV alloy based MQW TL. Strain balanced QW structure is considered to make it feasible for fabrication. The modulation bandwidth of TL with respect to the number of QW is examined during the analysis. The variation of optical confinement factor and modal gain for different number of QWs $(\mathrm{N})$ is also studied. The overall optical confinement factor and modal gain increase with N. However, the optical confinement factor per well and the rate of increment of modal gain with $\mathrm{N}$ decreases. Frequency response for MQWTL is evaluated by solving laser rate equation and continuity equation considering the virtual states as a conversion mechanism. Plot of modulation response reveals that the maximum modulation bandwidth is obtained as $14.76 \mathrm{GHz}$ for $\mathrm{N}=5$. The results concluded that 
the value of $\mathrm{N}$ needs to be judiciously selected to obtain a higher modulation bandwidth while optimizing the trade-off between $\mathrm{N}$ and device mechanism (TL or DL). The proposed TL operates in mid-infrared region (2-3 $\mu \mathrm{m})$. The results strengthen the idea that group IV based MQWTL has a very bright future to become a viable source for mid infrared photonic integrated circuits (PIC).

\section{Acknowledgement}

This work is partly supported by a project under CRS (Application ID: 1-5748741991), by NPIU a unit of MHRD, Govt. of India at Darbhanga College of Engineering, Darbhanga, Bihar, India

\section{Declarations}

It is confirmed that all data and materials as well as software application or custom code support their published claims.

\section{References}

[1] R. Soref, "Mid-infrared photonics in silicon and germanium" Nat. Photonics 4, 495, 2010.

[2] G. Q. Lo et al., "Silicon photonics technologies for monolithic electronic-photonic integrated circuit," ECS Transactions, vol. 28, pp. 3-11, 2010.

[3] Ryo Nagase "Fiber-optic interconnect technologies", Proc. SPIE 11286, Optical Interconnects XX, 112860E (28 February 2020); https://doi.org/10.1117/12.2549231.

[4] Principia Dardano, Maria Ferrara, "Integrated Photodetectors Based on Group IV and Colloidal Semiconductors: Current State of Affairs", Micromachines, Vol.11, 842(pp.1-24), 2020.

[5] P Pareek., M.K Das,. S.Kumar, "Responsivity calculation of group IV-based interband MQWIP", Journal of Computational Electronics, Vol. 17, pp. 319-328, 2018.

[6] D. Liang and J. E. Bowers, "Recent progress in lasers on silicon," Nature Photonics, Vol. 4, No. 8, pp. 511-517, July 2010.

[7] H. Rong, S. Xu, O. Cohen, O. Raday, M. Lee, V. Sih, and M. Paniccia, “A cascaded silicon Raman laser," Nature Photonics, vol. 2, no. 3, pp. 170-174, Feb. 2008.

[8] R. E. Camacho-Aguilera, Y. Cai, N. Patel, J. T. Bessette, M. Romagnoli, L. C. Kimerling, and J. Michel, "An electrically pumped germanium laser,” Optic Express, vol. 20, no. 10, pp. 11316-11320, May 2012.

[9] R. Soref, D. Buca and S. Q. Yu, “Group IV Photonics: Driving Integrated Optoelectronics”, Optics and Photonics news, vol. 27, issue 1, pp-32-39,2016.

[10] R. Soref, "Emerging SiGeSn integrated-photonics technology", 2016 IEEE Photonics Society Summer Topical Meeting Series (SUM), CA, pp. 100-101. 2016. (doi: 10.1109/PHOSST.2016.7548747)

[11] J. Kouvetakis, J. Menedez, A.V.G. Chizmeshya., "Tin based group IV semiconductors: new platforms for opto and micro electronics and silicon," Ann. Rev. of Mat. Res., Vol.36, pp.497-554, 2006.

[12] Ravi Ranjan and Mukul K Das "Theoretical estimation of optical gain in Tin incorporated group IV alloy based transistor laser" Optical and Quantum Electronics, Vol.48, Article no. 201, March 2016.

[13] Ravi Ranjan, Mukul K Das and S Kumar, " Performance analysis of tin-incorporated group-IV alloy bsed transistor laser” Optics and Laser technology, Vol. 106, pp-228-233, April 2018.

[14] Ravi Ranjan, Prakash Pareek, Syed Sadique Anwer Askari and Mukul Kumar Das, "Performance Analysis of GeSn Alloy Based Multiple QuantumWell Transistor Laser" Proc. SPIE 10526, Physics and Simulation of Optoelectronic Devices XXVI, 105262A, San Francisco, US, Jaunary 2018.

[15] B. Mukhopadhyay, G. Sen, S. De, R. Basu, V. Chakraborty and P. K. Basu, "Calculated Characteristics of a Transistor Laser Using Alloys of Gr-IV Elements" Physica Status Solidi B, Vol. 255, p. 1800117, 2018.

[16] R. Basu, J. kaur and A. k. Sharma, "Analysis of a Direct-Bandgap GeSn-Based MQW Transistor Laser for MidInfrared Applications" Journal of Electronic Materials, Vol. 48, pp.6335-6346, 2019.

[17] R. Basu, B. Mukhopadhyay, and P. K. Basu, "Analytical model for threshold base current of a transistor laser with multiple quantum wells in the base" IET Optoelectronics, Vol. 7, issue 3 ,pp. 71-73, 2013.

[18] R. Basu, B. Mukhopadhyay, and P. K. Basu, "Modeling Resonance-Free Modulation Response in Transistor Lasers With Single and Multiple Quantum Wells in the Base" IEEE Photonics Journal, vol. 4, no. 5, pp. 1572-1581, Oct. 2012.

[19] B Faraji, W Shi, D L Pulfrey and L Chrostowski, "Analytical modeling of the Transistor Laser" IEEE Journal of Selected Topics in Quantum Electronics, Vol.15, No.3, June 2009.

[20] C.G. Van de Walle, "Band lineups and deformation potentials in the model-solid theory" Physical Review B, Vol. 39, No.3, pp.1871-1883, 1989.

[21] H.Kroemer and H Okamoto, 'Some Design Considerations for Multi-Quantum-Well Lasers', Japanese Journal of Applied Physics, Vol .23, No. 8, pp. 970-974, 1984, doi: 10.1143/JJAP.23.970.

[22] R. Nagarajan, M. Ishikawa, T.Fukushima, R. S. Geels and J. E. Bowers, "High speed quantum-well lasers and carrier transport effects", IEEE Journal of Quantum Electronics, Vol. 28, No.10, pp. 1990-2008.,1992, doi: 10.1109/3.159508. 


\section{Figures}

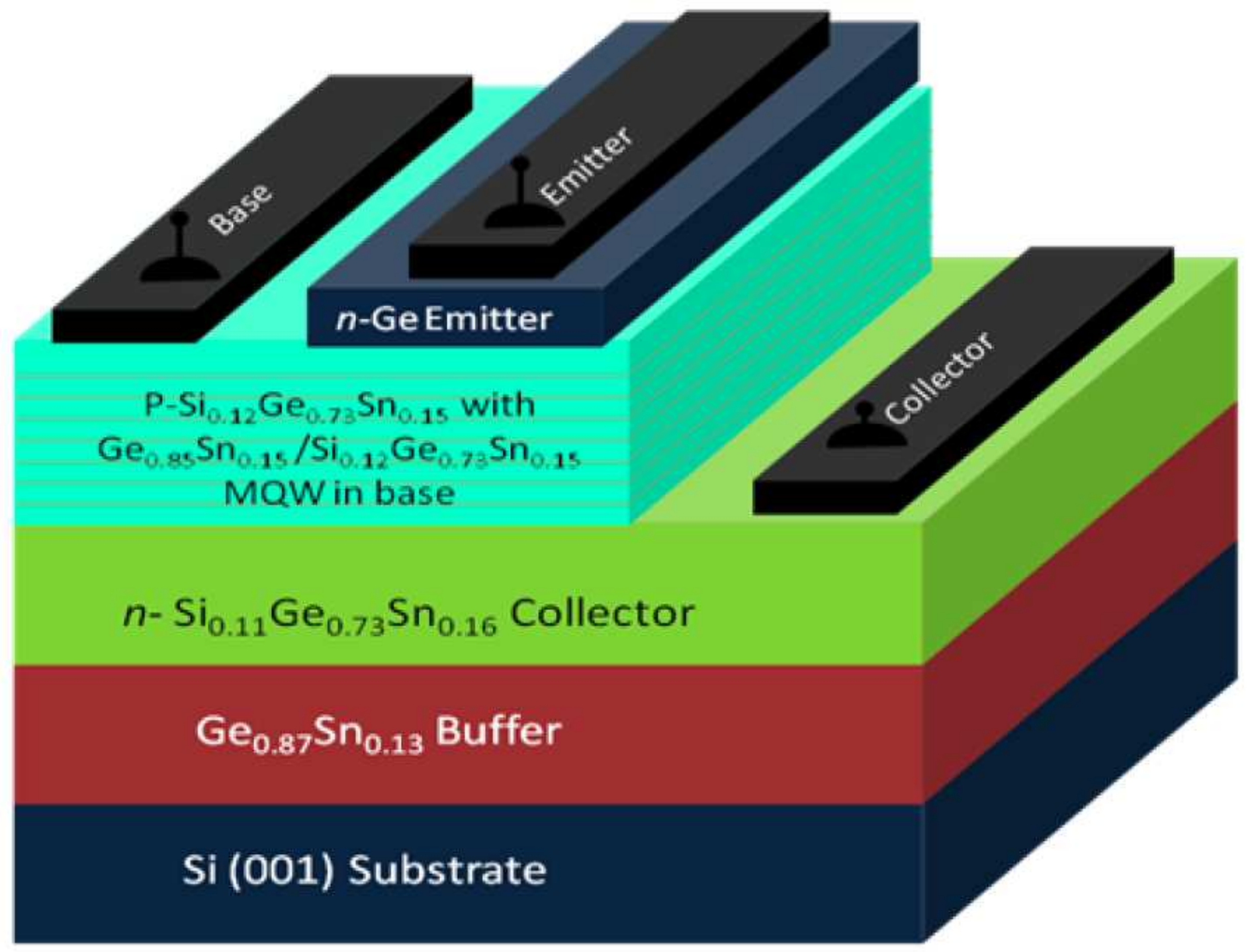

\section{Figure 1}

Schematic structure ofnpnGe-Si0.12Ge0.73Sn0.15- Si0.11Ge0.73Sn0.16 based transistor laser (TL) with strain-balanced i-Ge0,85Sn0.15 multiple quantum wells (MQW) in the base. 


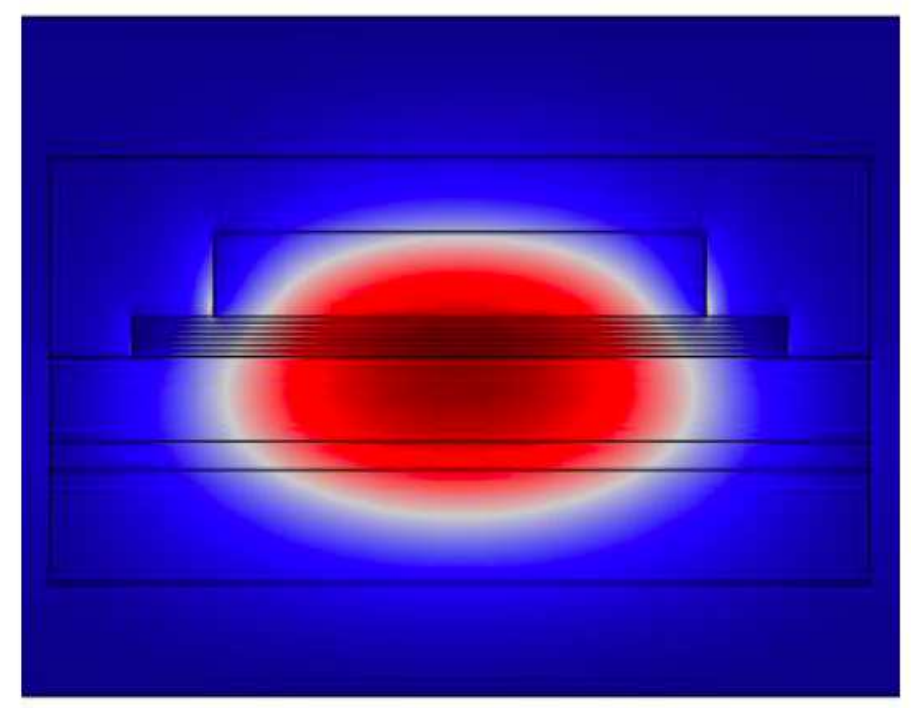

(a)

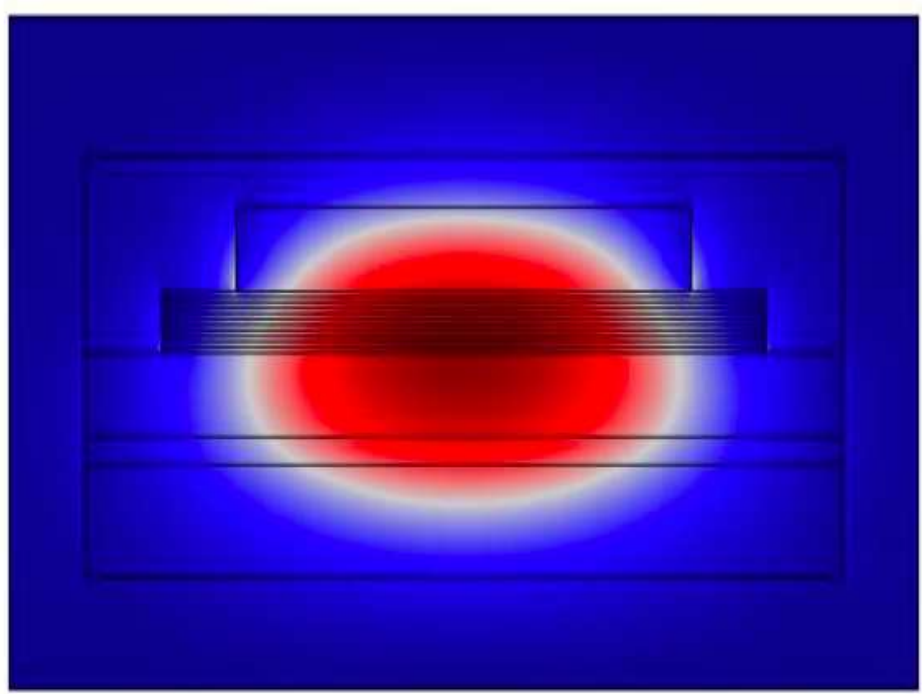

(b)

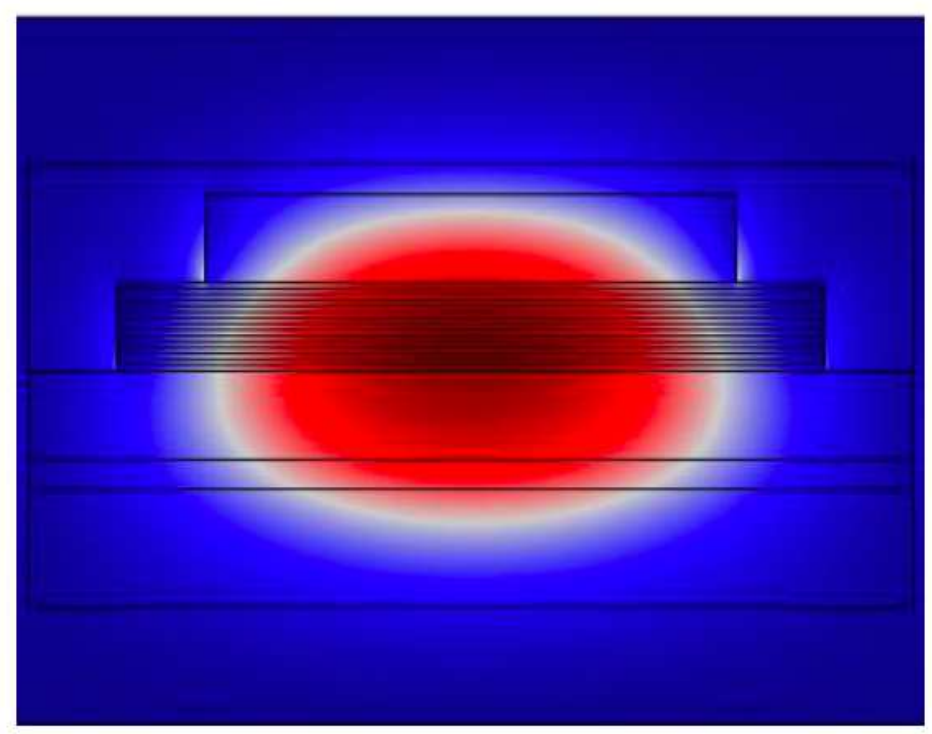

(c)

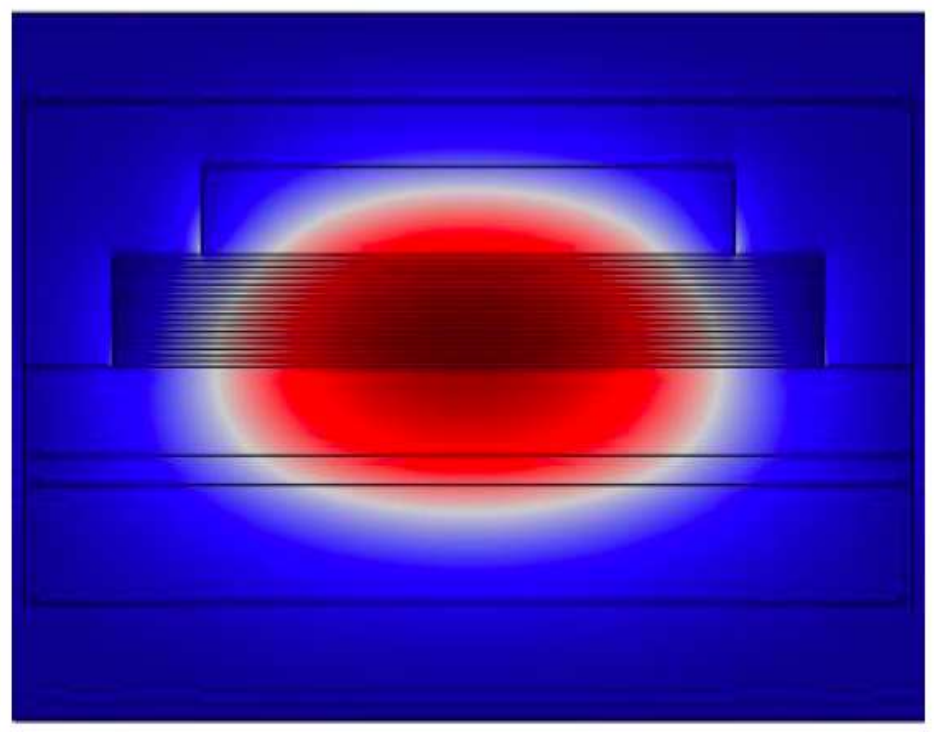

(d)

\section{Figure 2}

Field distribution of the TE field Ex for the quasi-TE fundamental mode at $\lambda=2.68 \mu \mathrm{m}$. The peak transverse electrical field is located near the active region, providing a QW optical confinement factor of (a) $7.07 \%$ for $\mathrm{N}=3$ (b) $11.4 \%$ for $\mathrm{N}=3$ (c) $15.5 \%$ for $\mathrm{N}=3$ (d) $19.00 \%$ for $\mathrm{N}=3$ 


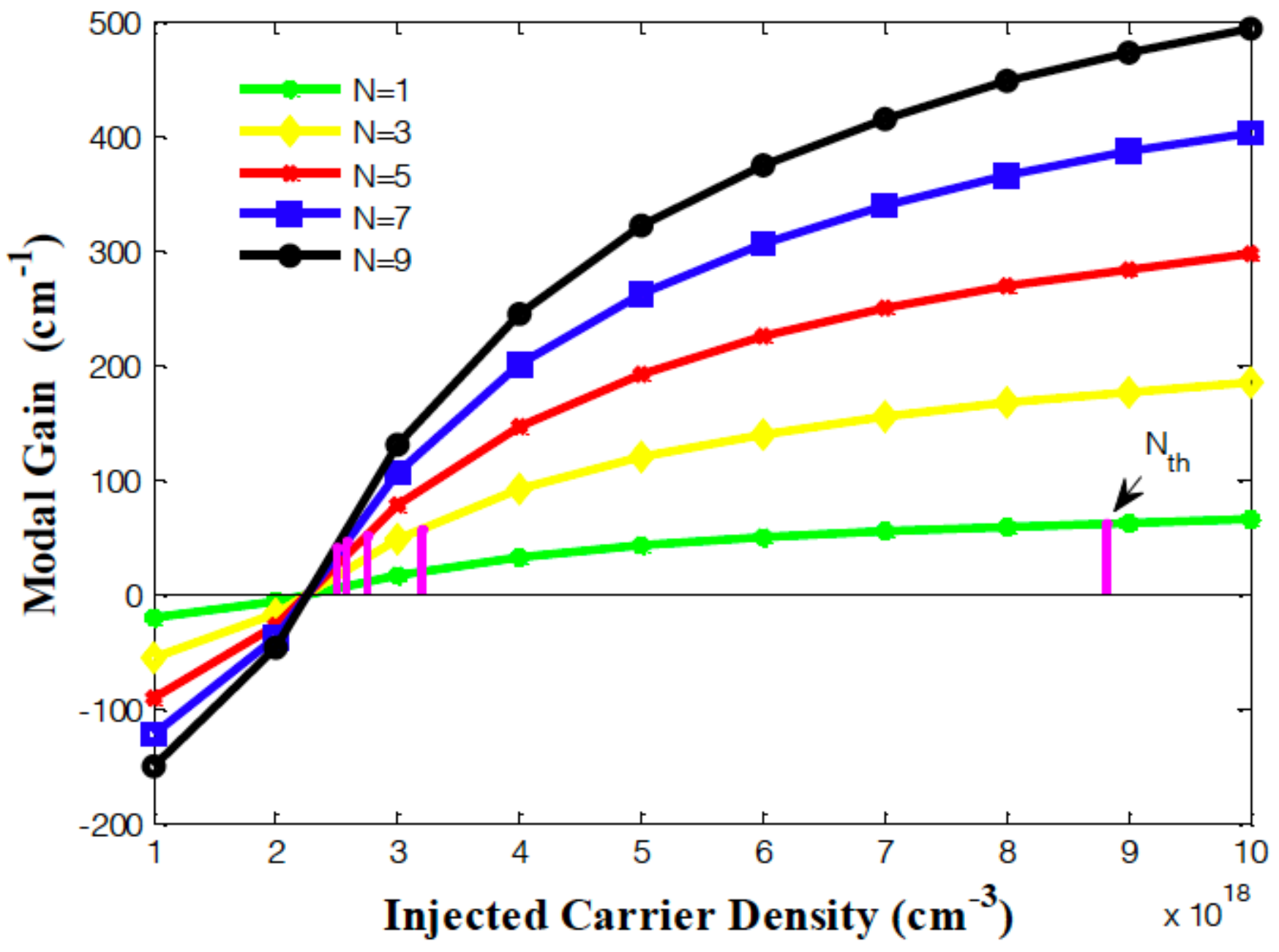

Figure 3

Plot of modal gain as a function of injected carrier density to obtained threshold carrier density 


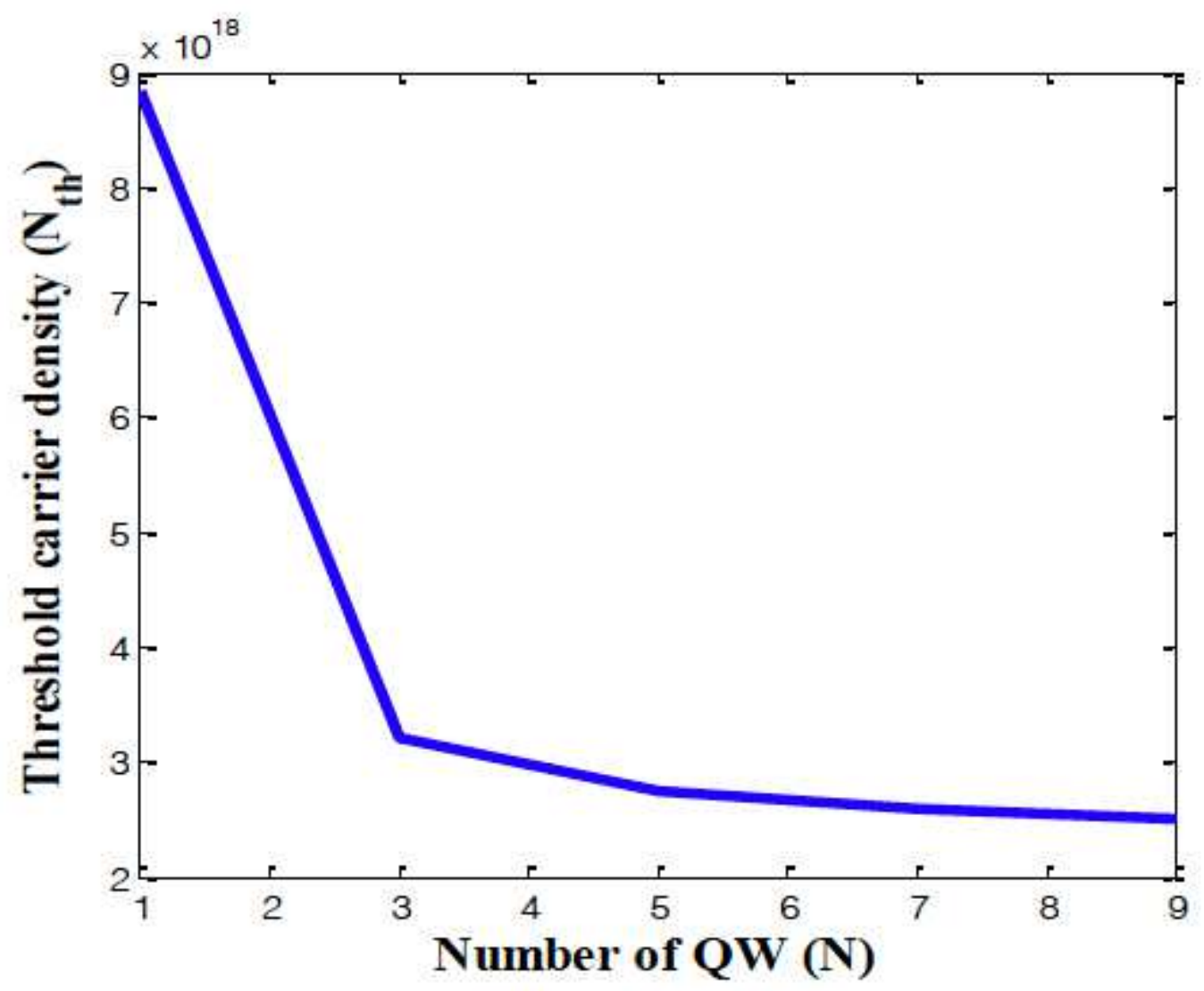

Figure 4

Threshold carrier density as a function of number of QW

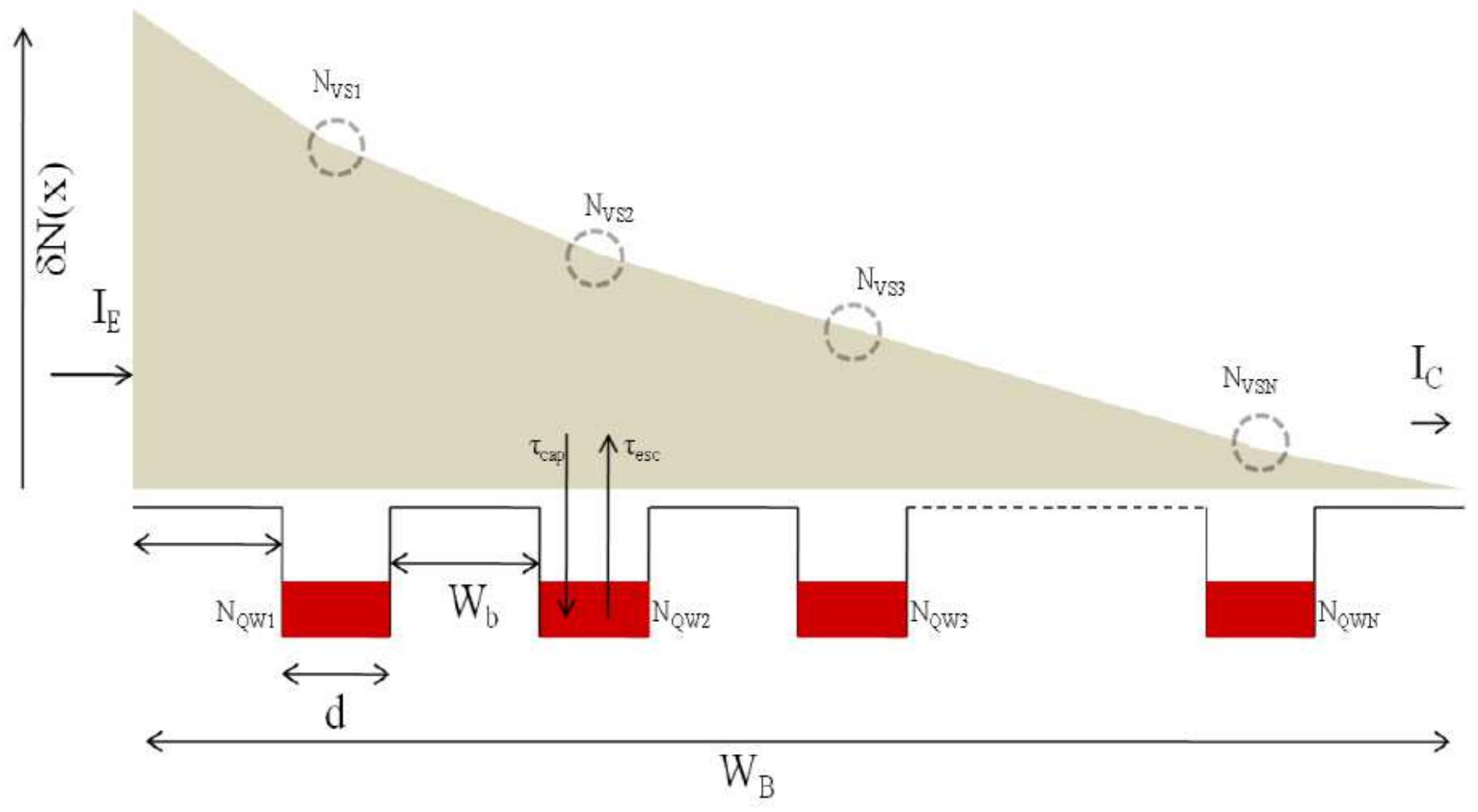


Figure 5

Schematic of carrier diffusion, quantum capture and escape in the MQW transistor laser

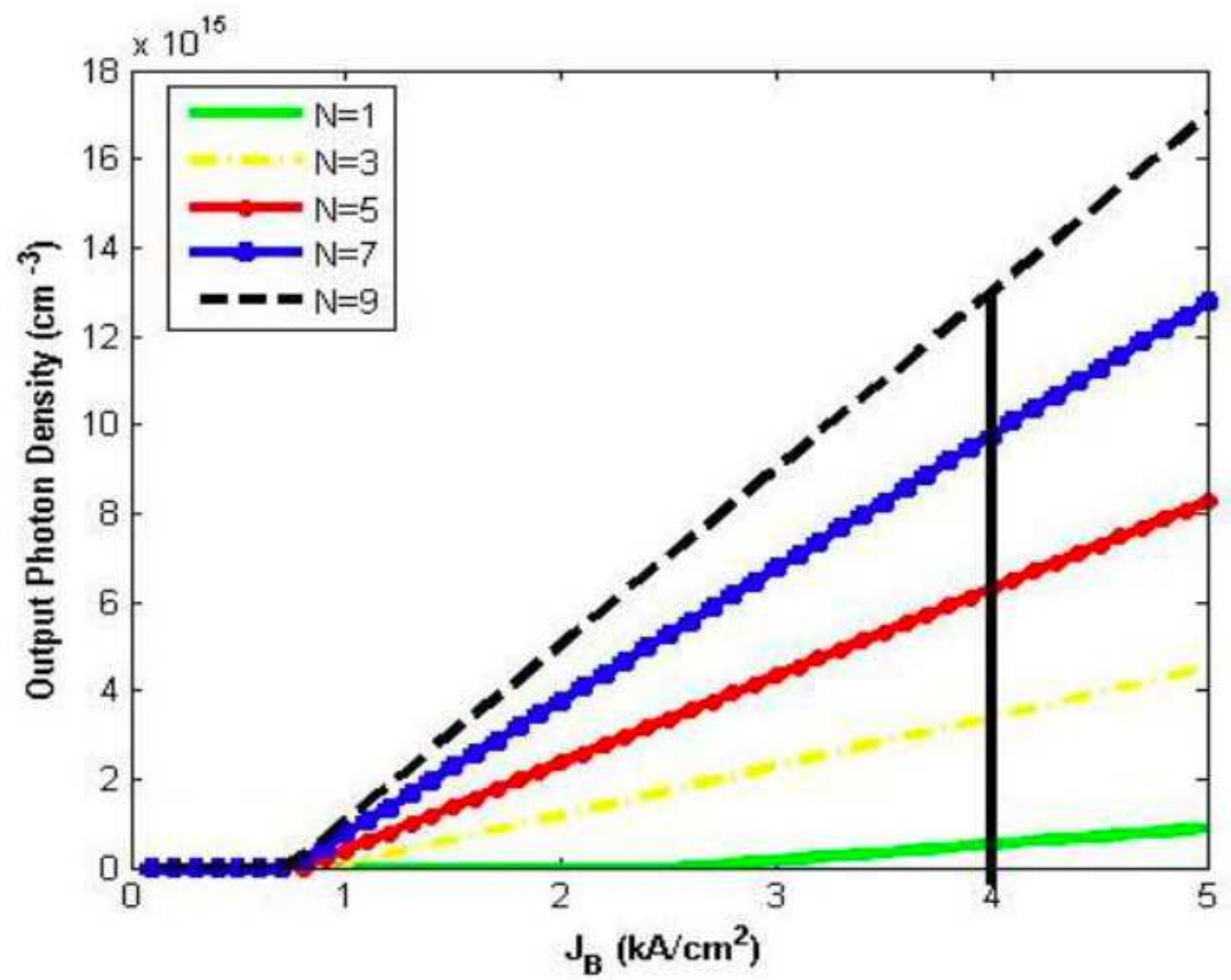

Figure 6

Plot of output photon density as a function of base current density for different $\mathrm{N}$ number of well 


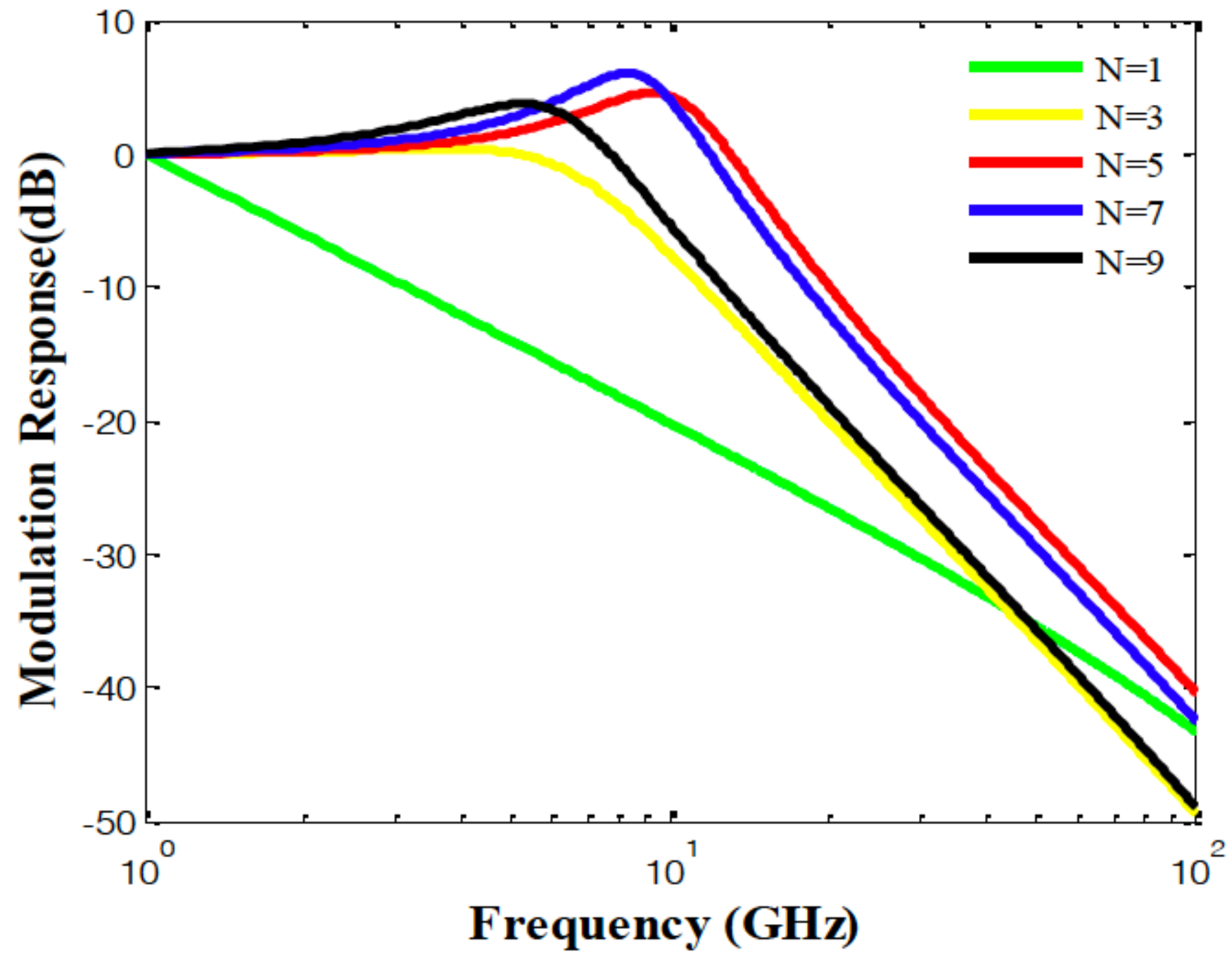

Figure 7

Modulation response with frequency for different number of QW 


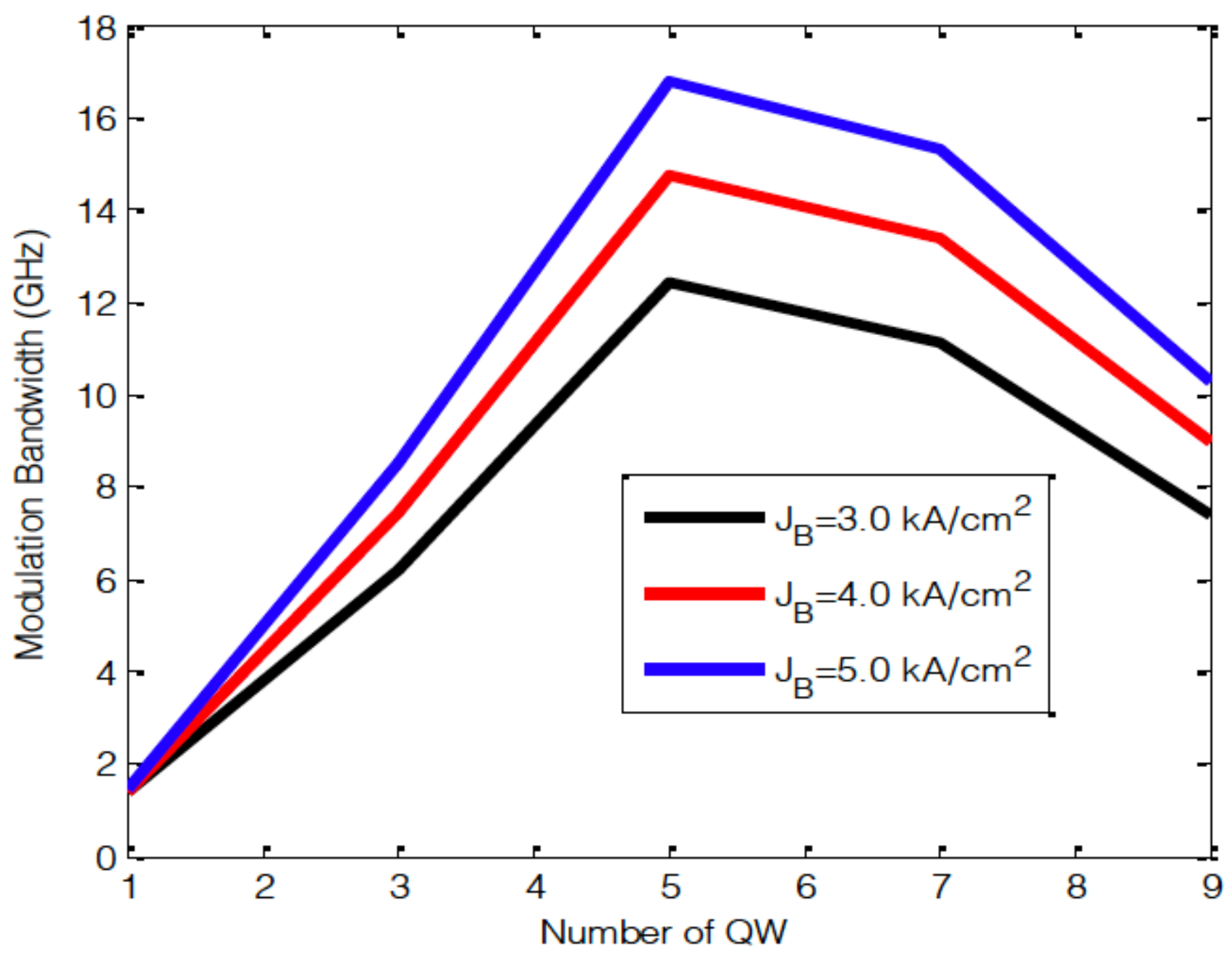

Figure 8

Modulation Bandwidth plotted as a function of number of well for different current density 